\title{
Interactions in Poly(vinyl chloride) Solutions
}

\author{
Lechoslaw A. UTRACKI* \\ Gulf Oil Canada Ltd., Shawinigan Chemicals Division, \\ Research Centre, P. O. Box 500, Ste-Anne-de-Bellevue, \\ Quebec, Canada.
}

(Received November 18, 1971)

\begin{abstract}
Molecular weight-intrinsic viscosity relations for poly(vinyl chloride) in five solvents were measured. It was found that the unperturbed dimension of the polymer coil depends on the nature of the solvent. The double cluster integral, $\beta$, was computed for this polymer in 35 solvents assuming the statistical segment to be equivalent to the monomeric unit. Subtracting from $\beta$ the polar interactions, $\beta_{\theta}$, calculated from the theory of Yamakawa, et al., a correlation between $\beta_{\mathrm{n}}=\beta-\beta_{\mathrm{e}}$ and the solvent solubility parameter $\delta_{1}$ was found to be similar to that of $\beta=\beta_{n}$ of nonpolar polymer-solvent systems. It has been found empirically that the data points can be separated into two relations; one for polymer-linear molecule solvents, and the second for polymer-non linear molecule solvents. It was demonstrated that this separation is consistent with the deficiency of the geometric mean rule of intermolecular interactions. This deficiency apparently originates in the "geometry" of the molecules, e.g., as expressed by the branching parameter $l_{12}$ in the work of Funk and Prausnitz.

KEY WORDS Polar Polymers / Poly(vinyl chloride) / Intrinsic Viscosity / Unperturbed Dimensions / Solubility / Long-Range Interaction /
\end{abstract}

In the framework of current theories ${ }^{1-3}$ the dilute solution properties of polymers are determined by the two interaction parameters:

$$
\begin{gathered}
A^{2}=a^{2} / M_{0}=\left\langle r_{\theta}{ }^{2}\right\rangle / M \\
B=\beta / M_{0}^{2}
\end{gathered}
$$

where $M$ and $M_{0}$ are the molecular weights of the polymer chain and of its statistical segment, respectively, $\left\langle r_{\theta}{ }^{2}\right\rangle$ is the mean sequare end-to-end distance, and $a$ and $\beta$ are the reduced short (A) and long (B)-range interaction parameters per one statistical segment, respectively. Only A and $B$ can be determined without any additional assumptions regarding the size of the statistical segment. However, often ${ }^{4,5}$ the interaction parameters are presented in the reduced forms assuming either $M_{0}=M_{0}{ }^{\mathrm{M}}=$ (molecular weight of one mer) or assuming $M_{0}=M_{0}{ }^{\mathrm{c}}=$ (molecular weight average per one carbon atom of the main chain). Often the long-range interaction parameter is expressed in the form of the

\footnotetext{
* Present address: Department of Chemical Engineering, McGill University, P.O. Box 6070 Montreal 101, Quebec, Canada.
}

Flory-Huggins interaction parameter ${ }^{4} \chi$. The relation between $\chi$ and $\beta$ was given by Flory and Fisk $^{6}$ as

$$
\beta=2\left(V_{0}^{2} / V_{1}\right)(1 / 2-\chi)
$$

where $V_{1}$ and $V_{0}$ are the molar volumes of the solvent and polymer segment, respectively. Assuming $V_{0}=V_{1}$ eq 3 can be expressed in the form quoted by Stockmayer ${ }^{7}$ or Yamakawa, et $a l^{8}$ The parameter, $B$, can be calculated from the thermodynamic measurement data. However, recently, Tanaka, et al. ${ }^{1}$ showed that a good numerical agreement can be achieved between $B$-values computed from the thermodynamic data with those calculated from intrinsic viscosities ([n]), provided the Stockmayer-Fixman $[\eta]-M$ relation is modified as follows

$$
[\eta] / M^{1 / 2}=1.05 \Phi A^{3}+0.287 \Phi B M^{1 / 2}
$$

where, on the basis of experiment the FloryFox constant $\Phi=2.5 \times 10^{21}$. Equation 4 can be derived from the empirical correlation ${ }^{1}$ :

$$
[\eta] /[\eta]_{\theta}=\alpha_{\eta}{ }^{3}=1.05+0.87 z, \quad 0<z<1.6
$$




\section{A. Utracki}

where

$$
z=\left(3 / 2 \pi A^{2}\right)^{3 / 2} B M^{1 / 2}
$$

and the $\theta$-subscript refers to the unperturbed conditions under which $z=0$. In the recent test of two-parameter theories, ${ }^{1,2}$ the authors concluded that the best correlation between the linear expansion coefficient $\alpha^{2}=\left\langle r^{2}\right\rangle\left\langle\left\langle r_{\theta}{ }^{2}\right\rangle\right.$ and $z$ is provided by the Yamakawa-Tanaka ${ }^{9}$ equation:

$$
\alpha^{2}=0.541+0.459(1+6.04 z)^{0.46}
$$

Writing

$$
\alpha_{\eta}{ }^{3}=\alpha^{n}
$$

one can calculate the exponent $n$ in terms of eq 5 . The numerical analysis gives $n=n(z)$ as shown in Figure 1. It can be seen that for $z \rightarrow 0$, $n \rightarrow \infty$, due to the improper limit, $\alpha_{\eta}{ }^{3}(z=0)=1.05$, of eq 5 . However for $0.1 \leq z \leq 1.6$, the exponent $2.19 \leq n \leq 2.77$. The broken line in Figure 1

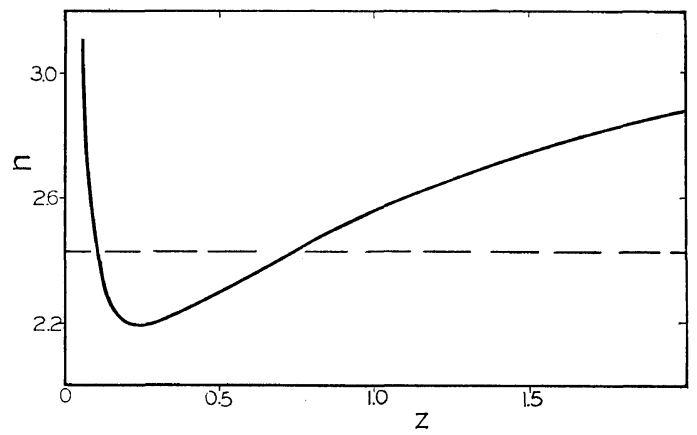

Figure 1. Correlation between the exponent $n$ (eq 8) and parameter $z$ calculated from equation of Tanaka, et al. (see text). The broken line marks the theoretical ${ }^{10}$ value $n=2.43$. marks the the value $n=2.43$, derived theoretically $^{10}$ for impermeable coils in solution. The value of the exponent $n=2.26$ was calculated by Utracki and Shimha ${ }^{11}$ for $z \leq 0.2$, in good agreement with the value computed from eq 5 and 7 . Furthermore, the average ratio of $\beta$ 's, determined $^{12}$ from the second virial coefficient, to $\beta$ 's calculated from the Stockmayer-Fixman relation, was found to be $2.02 \pm 0.25$, whereas the correction proposed by Tanaka, et al., to the Stockmayer-Fixman equation, increases the $\beta$ (or $B$ ) value by the factor 2.04 .

It is important to be able to predict $A$ and $B$ from the characteristic papameters of the pure compounds. Theoretically, $A$ does not depend on the solvent; experimentally this is not always true, but the observed variations are rather small. ${ }^{13} \quad B$, which depends primarily on the polymer-solvent interaction, determines the behaviour of a macromelecule at infinite dilution. Correlation between $B$ of the poly(vinyl chloride)(PVC) - solvent systems and the thermodynamic properties of pure components are of paramount interest.

\section{EXPERIMENTAL}

\section{Materials}

Polymers. Eight samples of PVC were polymerized by a free radical mechanism at $40-70^{\circ} \mathrm{C}$. The samples were precipitated and dried under vacuum. Molecular weights, $\boldsymbol{M}_{w}$ and $M_{n}$ of the samples were determined by a GPC and also calculated from the [ $\eta]$ 's in THF and cyclohexanone $(\mathrm{CHO})$ at $25.00^{\circ} \mathrm{C}$ using the Kratochvil, et al. ${ }^{14}$ relation and $M_{w} / M_{n}$ values

\begin{tabular}{|c|c|c|c|c|c|c|c|c|c|c|}
\hline \multirow{2}{*}{ No. } & \multirow{2}{*}{$\begin{array}{l}\text { Polymerization } \\
\text { method }\end{array}$} & \multirow{2}{*}{$\underset{{ }^{\circ} \mathbf{C}}{\operatorname{Temp}}$} & \multirow{2}{*}{$M_{w} / M_{n}$} & \multicolumn{3}{|c|}{$M_{w} \times 10^{-4}$} & \multicolumn{2}{|c|}{$s, \%$} & \multicolumn{2}{|c|}{$x, \%$} \\
\hline & & & & (GCP) & {$[\eta](T H F)$} & {$[\eta](\mathrm{CHO})$} & $\mathrm{KBr}$ & Film & $\mathrm{KBr}$ & Film \\
\hline 1 & UV irradiation & 40 & 2.64 & 20.6 & 24.0 & 23.5 & 63 & 63 & 4 & 6 \\
\hline 2 & Suspension & 45 & 2.69 & 14.7 & 14.5 & 14.5 & 63 & 63 & 3 & 2 \\
\hline 3 & Bulk & 50 & 1.94 & 9.04 & 9.39 & 9.63 & 65 & 64 & 3 & 5 \\
\hline 4 & Suspension & 57 & 2.26 & 7.74 & 9.50 & 8.64 & 57 & 63 & 3 & 4 \\
\hline 5 & Suspension & 63 & 2.31 & 7.10 & 7.70 & 7.76 & - & - & - & - \\
\hline 6 & Suspension & 60 & 2.08 & 5.20 & 5.98 & 6.01 & - & - & - & - \\
\hline 7 & Emulsion & 70 & 2.08 & 3.49 & 3.57 & 3.37 & 一 & - & - & - \\
\hline 8 & Emulsion & 70 & 1.74 & 1.05 & 1.30 & 1.05 & - & - & - & - \\
\hline
\end{tabular}
determined by the GPC method. The values

Table I. Characteristics of PVC samples 
are quoted in Table I.

Using an IR-spectrophotometer (Perkin-Elmer 255) the mole fraction of syndiotactic form ${ }^{15,16}$ $(s)$, and mole fraction of crystalline material ${ }^{17}$ $(x)$, in samples no. $1-4$, were determined. Parallel to these measurements, $s$ and $x$ were determined for samples polymerized under conditions similar to those of samples no. 5-8 used in this study. No significant differences from the data quoted in Table I were observed.

Solvents. The solvents were of the highest purity grade commercially available, and used without further purification.

Measurements. The [ $\eta]$ measurements were carried out in calibrated Cannon-Ubbelohde capillary viscometers. Measurements were made within $30 \mathrm{~min}$ after termination of the heating cycle. The kinetic energy $\operatorname{correction}^{18}$ was applied.

$$
\eta / d=A_{1} \tau-B_{1} / \tau^{2}
$$

$(\eta$, viscosity in $\mathrm{cP} ; d$, density in $\mathrm{g} / \mathrm{ml} ; \tau$, efflux time in sec; $A_{1}$ and $B_{1}$, viscometer constants).

\section{RESULTS}

The $[\eta]$ and Huggins constant $\left(k_{\mathrm{H}}\right)$ values were calculated from Huggins' and Kraemer's relations:

$$
\begin{aligned}
\eta_{\mathrm{sp}} / c & =[\eta]+k_{\mathrm{H}}[\eta]^{2} c \\
\left(\ln \eta_{\mathrm{r}}\right) / c & =[\eta]-k_{\mathrm{H}}[\eta]^{2} c \\
S & =k_{\mathrm{H}}+k_{\mathrm{K}}=1 / 2
\end{aligned}
$$

where $1+\eta_{\mathrm{sp}}=\eta_{\mathrm{r}}=\eta / \eta_{0}, \eta$ and $\eta_{0}$ are the absolute viscosities of solution and solvent respectively; $c$, concentration in $\mathrm{g} / \mathrm{d} l$. The parameter $S$,

\begin{tabular}{|c|c|c|c|c|}
\hline No. & Solvent & Code & $\begin{array}{l}\mathrm{d} l / \mathrm{g} \\
{[\eta],}\end{array}$ & $k_{\mathrm{H}}$ \\
\hline 1 & Acetone & A & - & - \\
\hline 2 & Acetic anhydride & AA & $\mathrm{ns}^{\mathrm{a}}$ & - \\
\hline 3 & Anisole & AN & 0.381 & 0.964 \\
\hline 4 & Benzonitrile & BN & 0.834 & 0.27 \\
\hline 5 & Benzoyl chloride & BYC & 0.842 & 0.38 \\
\hline 6 & Bromobenzene & BB & 0.710 & 0.32 \\
\hline 7 & Butanone & MEK & 0.818 & 0.29 \\
\hline 8 & Butyl acetate & BA & 0.75 & 0.55 \\
\hline 9 & Chlorobenzene & $\mathrm{CB}$ & 0.554 & 0.44 \\
\hline 10 & 2-Chlorobuta & $2 \mathrm{CBu}$ & $n s^{a}$ & - \\
\hline 11 & Chloroform & $\mathrm{CHCl}_{3}$ & - & - \\
\hline 12 & Cyclohexanone & $\mathrm{CHO}$ & 0.92 & 0.48 \\
\hline 13 & Cyclopentanone & $\mathrm{CPO}$ & - & - \\
\hline 14 & Di(n-butyl) phthalate & DBP & 0.91 & 0.53 \\
\hline 15 & Di(isobutyl) phthalate & DiBP & 1.10 & 0.26 \\
\hline 16 & $o$-Dichlorobenzene & ODCB & 0.71 & 0.58 \\
\hline 17 & Dichloroethane & DCE & - & - \\
\hline 18 & Di(ethyl) phthalate & DEP & 0.44 & 2.10 \\
\hline 19 & Di(2-ethylhexyl) phthalate & DOP & 0.18 & 0.28 \\
\hline 20 & $N, N$-Dimethylacetamide & DMA & 0.924 & 0.33 \\
\hline 21 & 3, 3-Di & $\mathbf{P}$ & 0.920 & 0.43 \\
\hline 22 & $N, N$-Dimethylformamide & DMF & 0.741 & 0.43 \\
\hline 23 & 1,4-Dioxane & $\mathrm{DX}$ & 0.670 & 0.57 \\
\hline 24 & 2-Ethoxyethyl acetate & CA & 0.477 & 0.49 \\
\hline 25 & Ethyl acetate & EA & $\mathrm{ns}^{\mathrm{a}}$ & - \\
\hline 26 & etoacetate & EAA & - & - \\
\hline 27 & 2-Furfural & FF & 0.63 & 0.44 \\
\hline 28 & 2-Hexanone & $\mathbf{H}$ & 0.944 & 0.40 \\
\hline 29 & Mesityl oxide & MO & 0.878 & 0.37 \\
\hline 30 & lidone & MY & 0.894 & 0.33 \\
\hline 31 & Nitrobenzene & NB & 0.850 & 0.42 \\
\hline 32 & $m$-Nitrotoluene & NT & 0.848 & 0.48 \\
\hline 33 & 3-Pentanone & PO & 0.892 & 0.45 \\
\hline 34 & Tetrac & TCE & - & - \\
\hline 35 & Tetrahydrofuran & THF & 0.971 & 0.38 \\
\hline
\end{tabular}
theoretically equal to $1 / 2$, for the whole series
Table II. $[\eta]$ and $k_{\mathrm{H}}$ data for PVC sample no. 4 at $25.00^{\circ} \mathrm{C}$ in various solvents

\begin{tabular}{|c|c|c|c|c|c|c|c|c|c|c|}
\hline \multirow{2}{*}{ No. } & \multicolumn{2}{|c|}{ THF } & \multicolumn{2}{|c|}{$\mathrm{CHO}$} & \multicolumn{2}{|c|}{ DOP } & \multicolumn{2}{|c|}{ DEP } & \multicolumn{2}{|c|}{ MO } \\
\hline & {$[\eta]$} & $k_{\mathrm{H}}$ & {$[\eta]$} & $k_{\mathrm{H}}$ & {$[\eta]$} & $k_{\mathrm{H}}$ & {$[\eta]$} & $k_{\mathrm{H}}$ & {$[\eta]$} & $k_{\mathrm{H}}$ \\
\hline 1 & 1.98 & 0.34 & 2.02 & 0.37 & 2.54 & - & 0.43 & - & 1.90 & - \\
\hline 2 & 1.34 & 0.40 & 1.40 & 0.25 & 1.77 & 0.32 & 0.51 & 1.32 & 1.29 & 0.35 \\
\hline 3 & 0.974 & 0.39 & 1.03 & 0.37 & 1.38 & 0.50 & 0.44 & 2.2 & - & - \\
\hline 4 & 0.971 & 0.39 & 0.92 & 0.48 & 1.18 & 0.28 & 0.44 & 2.1 & 0.878 & 0.37 \\
\hline 5 & 0.830 & 0.36 & 0.860 & 0.22 & 1.14 & 0.25 & - & - & - & - \\
\hline 6 & 0.684 & 0.37 & 0.706 & 0.35 & 0.884 & 0.47 & - & - & - & - \\
\hline 7 & 0.46 & 0.38 & 0.45 & 0.36 & 0.634 & 0.06 & - & - & - & - \\
\hline 8 & 0.219 & 0.51 & 0.181 & 0.61 & 0.292 & 0.15 & 0.159 & 1.02 & 0.204 & 0.51 \\
\hline
\end{tabular}

a ns, nonsoluble.

Table III. [ $\eta]$ and $k_{\mathrm{H}}$ values for PVC samples at $25.00^{\circ} \mathrm{C}$ 


\section{A. Utracki}

of data reported here, was found to vary from 0.47 to 0.55 .

The [ $\eta$ ]'s and $k_{\mathrm{H}}$ 's are given in Table II (sample no. 4 at $25.00^{\circ} \mathrm{C}$ in 35 solvents), Table III (samples no. $1-8$ at $25.00^{\circ} \mathrm{C}$ in five solvents), and Table IV (samples no. 4 in three solvents at four temperatures).

Table IV. Temperature dependence of $[\eta]$ for PVC sample no. 4

\begin{tabular}{|c|c|c|c|c|c|c|c|}
\hline \multirow{2}{*}{ Solvent } & $15.00^{\circ} \mathrm{C}$ & \multicolumn{2}{|c|}{$25.00^{\circ} \mathrm{C}$} & \multicolumn{2}{|c|}{$40.00^{\circ} \mathrm{C}$} & \multicolumn{2}{|c|}{$60.00^{\circ} \mathrm{C}$} \\
\hline & {$[\eta] \quad k_{\mathrm{H}}$} & {$[\eta]$} & $k_{\mathrm{H}}$ & {$[\eta]$} & $k_{\mathrm{H}}$ & {$[\eta]$} & $k_{\mathrm{H}}$ \\
\hline
\end{tabular}

\begin{tabular}{llllllllll}
\hline THF & 1.01 & 0.36 & 0.971 & 0.38 & 0.94 & 0.39 & - & -
\end{tabular}

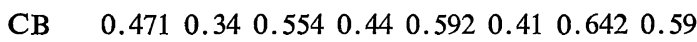

$\begin{array}{lllllllllllllll}\text { NB } & 0.891 & 0.31 & 0.850 & 0.42 & 0.843 & 0.47 & 0.800 & 0.50\end{array}$

\section{DISCUSSION}

Estimation of the Short-Range Interaction Parameter

The data from Table III are presented in Figure 2 according to eq 4 . It is important to note that the plot is linear as predicted by the relation. The results for PVC in the three good solvents: CHO, THF, and MO (for the solvent code see Table II) lead to the common intercept
$I=1.05 \Phi A^{3}=1.35 \times 10^{-3}$, whereas the data for PVC-DOP and PVC-DEP to $I=2.0 \times 10^{-3}$. The difference in $K_{\theta}=\Phi A^{3}$ for PVC was also reported by Bohdanecky. ${ }^{19,20}$

The ability of PVC molecules to associate has been frequently reported. ${ }^{21}$ For this reason the measurements were performed immediately after dissolution. During the preliminary experiments, the value of $[\eta]$ for sample no. 4 in DOP increased from the initial value of 1.18 to 1.38 after one day, and to 1.57 after two weeks. However, the initial viscosity of the solution was found to be stable for the first two hours. It was concluded that the data collected within the first $30 \mathrm{~min}$ after dissolution reflect the hydrodynrmic behavior of the individual macromolecules in solution.

\section{Mark-Houwink-Sakurada Relation}

The agreement between $M_{w}$ (GPC), $M_{w}$ (THF), and $M_{w}(\mathrm{CHO})$ indicate that the parameters of the relation

$$
[\eta]=K M_{w}{ }^{a}
$$

as reported by Kratochvil, et al., ${ }^{14}$ for PVC,

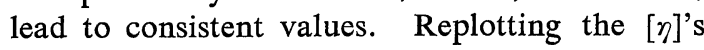
according to eq 11 we find that

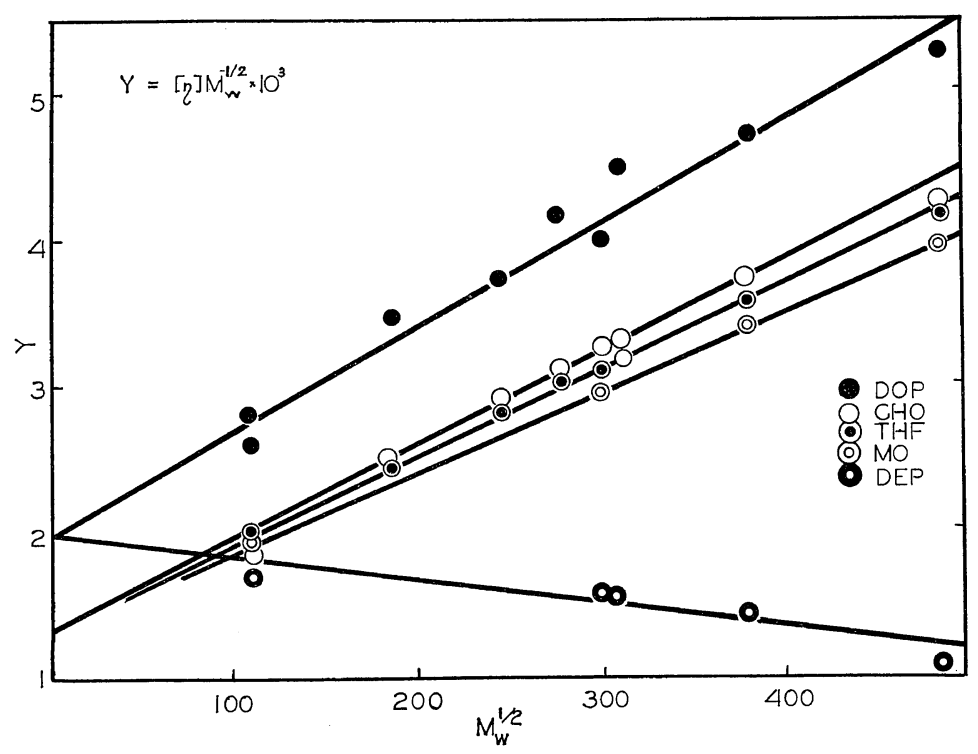

Figure 2. Plots of $[\eta] M_{w}^{-1 / 2} v s . M_{w^{1 / 2}}$ for poly(vinyl chloride) in di(ethylhexyl) phthalate (DOP), cyclohexanone (CHO), tetrahydrofuran (THF), mesityl oxide (MO), and di(ethyl) phthalate (DEP) at $25.00^{\circ} \mathrm{C}$. 


$\begin{array}{lll}\text { in DOP } & K=3.71 \times 10^{-4} & a=0.71 \\ \text { in DEP } & K=22.0 \times 10^{-4} & a=0.46 \\ \text { in MO } & K=1.93 \times 10^{-4} & a=0.74\end{array}$

\section{Huggins Constant}

Some years ago we proposed ${ }^{11}$ the relation:

$$
k_{\mathrm{H}}[\eta]=K_{1} M^{a_{1}} \text { or } k_{\mathrm{H}}=K_{2} M_{w}^{a_{1}-a}
$$

where $K_{1}$ and $a_{1}$ are empirical parameters. The value of $\Delta a=a_{1}-a$ is a measure of the molecular weight dependence of $k_{\mathrm{H}}$. For the solvents: THF, CHO, DOP, and MO, the values of $\Delta a$ are respectively $-0.05,0.00,0.46,0.56$, and -0.17 . Consequently, $k_{\mathrm{H}}$ decreases with $M_{w}$ for MO and THF, $k_{\mathrm{H}}=0.33$ in the whole range of $M_{w}$ for $\mathrm{CHO}$, and strongly increases with $M_{w}$ for the remaining two solvents. The linear flexible molecule exhibits the $k_{\mathrm{H}}-M_{w}$ behaviour observed for PVC in MO, THF, and CHO. The sharp increase of $k_{\mathrm{H}}$ with $M_{w}$ found for PVC in phthalates can be observed ${ }^{22}$ in systems in which intermolecular association was reported, viz., cellulose derivatives, polydienes, polyundecanoates, and crystalline polymers.

Another evidence for the association is presented in Figure 3. Here the Huggins

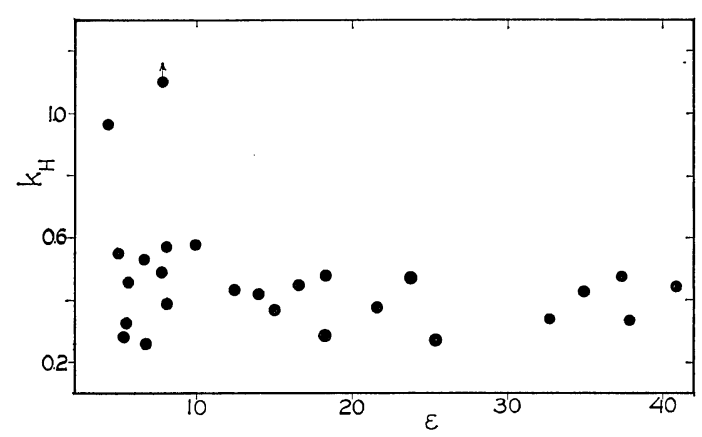

Figure 3. Dependence of Huggins constant, $k_{\mathrm{H}}$, for poly(vinyl chloride) sample no. 4 , at $25.00^{\circ} \mathrm{C}$ on solvent dielectric constant $\varepsilon$.

constants, $k_{\mathrm{H}}$, for sample no. 1 in 26 solvents are plotted vs. the dielectric constant of the solvent, $\varepsilon$. It is evident that $k_{\mathrm{H}}=0.4 \pm 0.1$ for $\varepsilon>10$, independently of of the other characteristics of the solvents. Conversely for $\varepsilon<10 k_{\mathrm{H}}=$ $0.25-2.10$. It was reported ${ }^{23}$ that microgelation in cis-polyisoprene-toluene- $25.00^{\circ} \mathrm{C}$ system lowers $k_{\mathrm{H}}$, whereas long-chain branching in- creases its value. ${ }^{24}$ If this observation is generally valid, then the high values of $k_{\mathrm{H}}$ for PVC in some low dielectric constant solvents (e.g., AN, CB, ODCB, DX, and BA) would suggest that the association is polar in character and probably occurs by an intramolecular mechanism.

\section{Long-Range Interactions}

It is generally assumed that the long-range interactions are of the dispersion type and only recently ${ }^{8,25}$ the dipolar type were also taken into account:

$$
\beta=\beta_{\mathrm{n}}+\beta_{\mathrm{e}}, \quad \beta_{\mathrm{e}} \leq 0
$$

where $\beta_{\mathrm{n}}$ and $\beta_{\mathrm{e}}$ are nonpolar and polar contribution to the binary cluster integral $\beta$. Yamakawa, et al., ${ }^{8}$ calculated $\beta_{\mathrm{e}}$ assuming that the spherical segments of a polar polymer, each with volume $V_{0}$, dipole moment $\mu$, polarizability $\bar{\alpha}$, and refractive index $n_{\mathrm{R}}$, interact in a continuum with the dielectric constant $\varepsilon$. In order to compute $\beta_{\mathrm{e}}$ for a given polymer-solvent system, one has to know $\mu, \bar{\alpha}, n_{\mathrm{R}}, \varepsilon$, and $V_{0}$ at a given temperature. Excepting for the last quantity, all the remaining parameters are experimentally available and the parameter

$$
\beta_{\mathrm{e}}{ }^{*}=-\beta_{\mathrm{e}} V_{0}
$$

can be calculated exactly

$$
\beta_{\mathrm{e}}^{*}=\frac{4 \pi^{2}}{3 \varepsilon^{2}}\left(\frac{3 \varepsilon}{2 \varepsilon+1}\right)^{4}\left(\frac{\mu^{* 2}}{3 k T}\right)\left(\frac{\mu^{* 2}}{3 k T}+\alpha^{*}\right)
$$

where

$$
\begin{aligned}
& \mu^{*}=\frac{2 \varepsilon+1}{2 \varepsilon+n_{\mathrm{R}}{ }^{2}}\left(\frac{n_{\mathrm{R}}{ }^{2}+2}{3}\right) \mu \\
& \alpha^{*}=\frac{2 \varepsilon+1}{2 \varepsilon+n_{\mathrm{R}}{ }^{2}}\left(\frac{n_{\mathrm{R}}+2}{3}\right) \bar{\alpha}
\end{aligned}
$$

However, in order to calculate $\beta_{\mathrm{e}}$ as well as $\beta$ itself, one has to assign a concrete value for the size of the statistical segment.

\section{Size of the Statistical Segment}

Within the framework of the Yamakawa, et al. theory, the monomeric unit seems to be the only logical choice for the statistical segment-the dipole moment, $\mu$, in eq 16 is taken as numerically equal to that of a molecule analogous to the monomeric unit. In this paper $V_{0}$ is culculated from the relation: 


\section{A. Utracki}

$$
V_{0}=M_{0} / \rho
$$

where $\rho$ is the polymer density. Taking the density of amorphous $\mathrm{PVC}^{26}: \rho_{25}=1.385(\mathrm{~g} / \mathrm{m} l)$, $V_{0}=74.93 \AA^{3}$ was found. Consistently, the $M_{0}$ in eq 2 and 18 is considered to represent the molecular weight per one mer.
Computation of the Interaction Parameters

Values of $\beta$, calculated from the data of Table II using eq 2 and 4 , and $\beta_{e}$ computed from eq 15-17 are given in Table V. In the calculations the following values were adopted: $I=2 \times 10^{-3}$ for phthalates and $1.35 \times 10^{-3}$ for all other solvents and $\mu=1.64$ (D) (see ref 27). The value $\bar{\alpha}=5.699 \times 10^{-24}$ was computed from the

Table V. Interaction parameters for PVC solutions at $25.00^{\circ} \mathrm{C}$

\begin{tabular}{|c|c|c|c|c|c|c|c|c|c|}
\hline \multirow{2}{*}{ No. } & \multirow{2}{*}{ Code } & \multirow{2}{*}{$\varepsilon^{a}$} & \multirow{2}{*}{$\begin{array}{c}\delta_{1}, \\
\mathrm{cal} / \mathrm{cm}^{3} \mathrm{a}, \mathrm{b}\end{array}$} & \multicolumn{2}{|c|}{$\beta, \AA^{3}$} & \multirow{2}{*}{$-\beta_{\mathrm{e}}, \AA^{3}$} & \multicolumn{2}{|c|}{$\beta_{\mathrm{n}}, \AA^{3}$} & \multirow{2}{*}{ Symmetry } \\
\hline & & & & $U^{\mathrm{a}}$ & $B^{* a}$ & & $U^{\mathrm{a}}$ & $B^{* \mathrm{a}}$ & \\
\hline 1 & A & 20.7 & 9.62 & - & 12.71 & 4.40 & - & 17.11 & $\mathrm{~L}$ \\
\hline 2 & AA & 20.1 & 10.65 & $\mathrm{~ns}^{\mathrm{a}}$ & - & 4.61 & $<4.61$ & - & $\mathrm{L}$ \\
\hline 3 & AN & 4.33 & $9.68^{\mathrm{f}}$ & -1.45 & 14.10 & 47.37 & 45.91 & 61.46 & $\mathbf{S}$ \\
\hline 4 & $\mathrm{BN}$ & 25.2 & $10.6^{\mathrm{f}}$ & 25.95 & - & 3.06 & 29.01 & - & $\mathbf{S}$ \\
\hline 5 & BYC & 21.5 & $10.1^{\mathrm{f}}$ & 26.43 & - & 4.07 & 30.50 & - & S \\
\hline 6 & BB & 5.4 & $9.87,8.9^{j}$ & 18.45 & 18.00 & 35.36 & 53.81 & 53.36 & $S$ \\
\hline 7 & MEK & 18.07 & 9.45 & 24.98 & 16.89 & 5.47 & 30.45 & 27.36 & $\mathbf{L}$ \\
\hline 8 & BA & 4.94 & 8.69 & 20.87 & 22.75 & 40.04 & 61.63 & 62.79 & $\mathrm{~L}$ \\
\hline 9 & CB & 5.621 & 9.67 & 8.17 & 16.06 & 33.37 & 41.54 & 49.43 & $\mathrm{~S}$ \\
\hline 10 & $2 \mathrm{CBu}$ & $8.37^{\mathrm{c}}$ & $8.03^{\mathrm{f}}$ & $\mathrm{ns}^{\mathrm{a}}$ & - & 19.74 & $<19.74$ & - & $\mathrm{L}$ \\
\hline 11 & $\mathrm{CHCl}_{3}$ & 4.718 & 9.16 & - & 15.78 & 42.71 & - & 58.99 & $\mathbf{S}$ \\
\hline 12 & $\mathrm{CHO}$ & 18.2 & 10.42 & 31.15 & 34.60 & 5.47 & 36.62 & 40.07 & $\mathbf{S}$ \\
\hline 13 & $\mathrm{CPO}$ & $13.3^{b}$ & 10.53 & - & 27.07 & 9.34 & - & 36.41 & $\mathbf{S}$ \\
\hline 14 & DBP & 6.535 & 9.85 & 18.75 & - & 28.02 & 46.77 & - & $\mathbf{S}$ \\
\hline 15 & DiBP & $6.69^{c}$ & $9.15^{f}$ & 30.25 & - & 26.69 & 56.94 & - & $\mathbf{S}$ \\
\hline 16 & ODCB & 9.93 & 10.04 & 18.45 & - & 15.08 & 33.53 & - & $\mathbf{S}$ \\
\hline 17 & DCE & 9.84 & 8.92 & - & 20.10 & 15.34 & - & 35.44 & $\mathrm{~L}$ \\
\hline 18 & DEP & $7.63^{\mathrm{c}}$ & 9.97 & -9.68 & - & 22.28 & 12.60 & - & $\mathbf{S}$ \\
\hline 19 & DOP & $5.25^{\mathrm{c}}$ & $8.91 \mathrm{~g}$ & 35.09 & - & 37.36 & 72.45 & - & $\mathbf{S}$ \\
\hline 20 & DMA & $37.8^{\mathrm{e}}$ & $10.8^{f}$ & 31.40 & - & 1.41 & 32.81 & - & $\mathbf{S}$ \\
\hline 21 & $\mathbf{P}$ & 12.45 & 8.22 & 31.16 & - & 10.54 & 41.70 & - & $\mathrm{L}$ \\
\hline 22 & DMF & $37.2^{\mathrm{e}}$ & $11.7^{\mathrm{f}}$ & 20.33 & 18.90 & 1.46 & 21.79 & 20.36 & $\mathbf{S}$ \\
\hline 23 & DX & 2.209 & 10.13 & 16.03 & 16.75 & 84.08 & 100.11 & 100.83 & $\mathbf{S}$ \\
\hline 24 & CA & 7.725 & 9.35 & 4.36 & - & 21.76 & 26.12 & - & $\mathrm{L}$ \\
\hline 25 & EA & 6.02 & 8.21 & $\mathrm{~ns}^{\mathrm{a}}$ & 17.03 & 30.69 & $<30.69$ & 47.72 & $\mathrm{~L}$ \\
\hline 26 & EAA & $16.5^{b}$ & $9.83 \mathrm{~g}$ & - & 10.48 & 6.54 & - & 17.02 & $\mathrm{~L}$ \\
\hline 27 & FF & 40.73 & $11.2^{\mathrm{f}}$ & 13.61 & - & 1.22 & 14.83 & - & $\mathbf{S}$ \\
\hline 28 & $\mathrm{H}$ & 13.88 & 8.63 & 32.60 & - & 8.81 & 41.41 & - & $\mathrm{L}$ \\
\hline 29 & MO & 15.0 & 9.19 & 28.61 & - & 7.67 & 36.28 & - & $\mathrm{L}$ \\
\hline 30 & MY & $32.5^{\mathrm{e}}$ & $11.2^{\mathrm{f}}$ & 28.17 & - & 1.52 & 29.69 & - & $\mathbf{S}$ \\
\hline 31 & NB & 34.82 & $10.67 \mathrm{~g}$ & 27.52 & 20.24 & 1.67 & 29.19 & 20.91 & $\mathbf{S}$ \\
\hline 32 & NT & 23.55 & $10.4^{\mathrm{h}}$ & 26.80 & - & 3.47 & 30.27 & - & $\mathbf{S}$ \\
\hline 33 & PO & 16.57 & 9.06 & 29.46 & - & 6.40 & 35.86 & - & $\mathrm{L}$ \\
\hline 34 & TCE & $8.15^{b}$ & $9.7^{\mathrm{i}}$ & - & 22.61 & 20.15 & - & 42.76 & $\mathbf{S}$ \\
\hline 35 & THF & $8.0^{\mathrm{d}}$ & $9.52 \mathrm{~g}$ & 34.18 & 27.21 & 20.80 & 54.98 & 48.01 & $\mathbf{S}$ \\
\hline
\end{tabular}

a $U$, this work; ns, nonsoluble; b $B^{*}$, data taken from ref 19; values of $\varepsilon$ and $\delta_{1}$, taken from ref 29 and 30 respectively. b "Beilsteins Handbuch der Organischen Chemie," 4th ed, Berlin, 1955. c Determined by Dr. J. A. Jukes in this laboratory. ${ }^{\mathrm{d}} \operatorname{Ref} 31 .{ }^{\ominus} \operatorname{Ref} 32 .{ }^{\mathrm{f}} \operatorname{Ref} 33 .{ }^{\mathrm{g}} \operatorname{Ref} 34 .{ }^{\mathrm{h}} \operatorname{Ref} 35 .{ }^{\mathrm{i}} \operatorname{Ref} 36$. j Ref 37. 
Clausius-Mossotti equation

$$
\bar{\alpha}=\left(3 V_{0} / 4 \pi\right) \frac{n_{\mathrm{R}}{ }^{2}-1}{n_{\mathrm{R}}{ }^{2}+2}
$$

using $n_{\mathrm{R}}=1.550$ determined from the $\left(\mathrm{d} n_{\mathrm{R}} / \mathrm{d} c\right)$ vs. $n$ plot $^{28}$ ( $n$ is solvent refractive index). The dielectric constant $\varepsilon$, and the solubility parameter $\delta_{1}$ are also quoted in the Table. In addition, [ $\eta]$ data for PVC solutions reported by Bohdanecky ${ }^{19}$ were recalculated. Finally, the nonpolar interaction parameter, $\beta_{n}$, was computed from eq 13. Both sets of data, those of ref 19 and our own, yield very similar numerical values of $\beta_{\mathrm{n}}$. As before, all 35 solvents were subdivided into two groups, di(alkyl) phthalates constituting the first and all remaining the second. The unperturbed dimensions in these two groups were assumed to be different, but independent of the nature of the solvent within the group. This assumption is based on the data shown in Figure 2 and, strictly speaking, is valid only for these five investigated solvents. For the remaining ones, the error introduced by this assumption can be calculated from eq 2 and 4:

$$
\Delta \beta=-\left(M_{0}^{2} / 0.301 \Phi M^{1 / 2}\right) \Delta I
$$

where

$$
\begin{aligned}
& I=1.05 \Phi A^{3}, \quad \Delta I=I_{\text {true }}-1.35 \times 10^{-3} \\
& \Delta \beta=\beta_{\text {true }}-\beta
\end{aligned}
$$

From eq 20 assuming that $1.35<I_{\text {true }} \times 10^{3}<2.0$ one can calculate for sample no. 4

$$
\beta-11.23 \leq \beta_{\text {true }} \leq \beta
$$

i.e., the assumption can lead to an overestimation of $\beta$ by as much as $11.23 \AA^{3}$.

\section{Solubility Parameter}

Recently the concept of solubility parameter is receiving renewed interest. It has been shown ${ }^{38}$ that the Berthelot geometric mean rule is not obeyed even for saturated aliphaticaromatic hydrocarbon mixtures and an extra parameter is needed to describe the system. This parameter was found to be a function of the shape of the interacting molecules.

For a very practical reason it was imperative to extend the solubility concept to other types of liquids than the original nonelectrolytes.
Years ago Hildebrand and $\operatorname{Scott}^{39}$ postulated that, in case of polar liquids

$$
\delta^{2}=\frac{\Delta E_{\mathrm{v}}}{V}=\delta_{\mathrm{n}}^{2}+\delta_{\mathrm{p}}{ }^{2}
$$

where $\Delta E_{\mathrm{v}}$ and $V$ are molar energy of vaporization and molar volume of the liquid respectively, $\delta_{\mathrm{n}}$ and $\delta_{\mathrm{p}}$ are the nonpolar and polar contributions to the solubility parameter. Recently Hansen $^{34}$ added another, hydrogen bonding term, $\delta_{\mathrm{h}}{ }^{2}$ to the right hand side of eq 22. Bagley, et al., ${ }^{40}$ determined that the internal pressure, $\boldsymbol{P}_{\mathrm{i}}$, describes the volume dependent solubility parameter $\delta_{\mathrm{v}}{ }^{2}={\delta_{\mathrm{n}}}^{2}+\delta_{\mathrm{p}}{ }^{2}$, whereas $\delta_{\mathrm{h}}{ }^{2}=\left(\Delta E_{\mathrm{v}} / V\right)-\boldsymbol{P}_{\mathrm{i}}=\delta_{\mathrm{r}}{ }^{2}$ is the residual solubility parameter. The concept of the solubility parameter, imperfect as it is, was found $^{41}$ to be equivalent, in predicting the $\chi$ dependence on temperature, pressure, chain length, and polymer flexibility, to that of the new sophisticated corresponding states theory. ${ }^{42}$

The interaction parameter, $\chi$, can be expressed as a sum of enthalpic $(\kappa)$ and entropic $(1 / 2-\Psi)$ contributions. Assuming that the solubility parameter theory ${ }^{43}$ is strictly applicable to the enthalpic part only, eq 3 can be rewritten as

$$
\beta / 2 V_{0}^{2}=\left(\Psi / V_{1}\right)-\frac{1}{R T} \sum_{i}\left(\delta_{1_{\mathrm{i}}}-\delta_{2_{\mathrm{i}}}\right)^{2}
$$

where subscripts 1 and 2 refer to solvent and polymer respectively and $i=n$ for nonpolar system, $i=n, p, h$ for the Hansen and $i=v, r$ for the Bagley, et al. approach, respectively.

From the data of Table V, correlation between $\beta$ and $\delta_{1}$ was found to be nonexistant. Similar negative results were obtained in analyzing the $\beta$-solubility parameters relation according to the Hansen formula, using his own values of $\delta_{1_{1}}$. A random scatter of $\beta$ values on the $\left(\delta_{1 v}\right.$, $\delta_{1 \mathrm{r}}$ ) plot was obtained.

In the next attempt $\beta_{\mathrm{n}}$, computed as described above, was plotted vs. Hildebrand's $\delta_{1}$. The result is shown in Figure 4 . It can be seen that all the data points can be divided into two groups; these calculated from the PVClinear molecule solvents (marked $\mathrm{L}$ in the last column of Table $\mathrm{V}$ ) and the others calculated from the PVC-nonlinear molecule solvent (coded $\mathrm{S}$ in the last column of Table V). To the first group, the data from aliphatic ketones, 


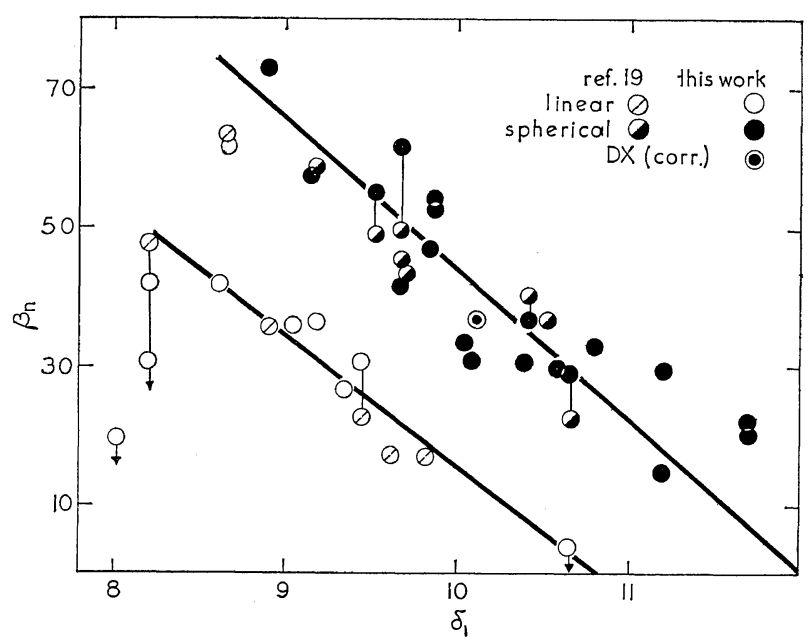

Figure 4. Non polar contribution $\beta_{n} v s$. solvent solubility parameters $\delta_{1}$ for poly(vinyl chloride). The data are arbitrarily separated into linear molecule solvents $(\oslash, \bigcirc)$ and spherical molecule solvents $(\varnothing, \varnothing)$. The vlaues are computed from ref $19(\oslash, \oslash)$ and the results of this work. Points connected with a bar represent the same solvent data as by ref 19 and this work. Dioxane data, calculated assuming $\varepsilon(\mathrm{DX})=\varepsilon(\mathrm{THF})$, are marked by $\odot$.

halides, amines, and esters were assigned; to the second, the data from all cyclic (saturated and unsaturated) solvents and solvents of small molecules of more-or-less spherical symmetry (e.g.; chloroform, tetrachloroethane). No attempt was made to correlate the vertical shift of the data points with a symmetry parameter or with a ratio of the molecular surface area as suggested in the literature. ${ }^{38,42}$ The data points marked by arrows are those calculated for nonsolvents. The vertical bar indicates the possible error introduced by assuming $I=1.35 \times$ $10^{-2}$ for all non phthalic solvents, as in eq 21 . Two data points did not follow the common trend: diethyl phthalate $\left(\beta_{\mathrm{n}}=12.60\right)$ and dioxane $\left(\beta_{\mathrm{n}}=100.11\right)$. In the first case, the very large $k_{\mathrm{H}}=2.10$ and the irregular [ $\left.\eta\right]$ vs. $M$ dependence indicate that probably no true solution was formed. In the second case, the low value of $\varepsilon$ results in a large value of $-\beta_{\mathrm{e}}=84 \AA^{3}$. The theory $^{8}$ of Yamakawa, et al., considers the dipolar interaction of polymer segments only; the solvent plays the role of a passive dielectric insulator. This approximation cannot be valid generally. In fact, a solvent with a high dipole moment must interact with polymer dipoles. On the atomic scale, probably the important parameter is the dipole of the interacting group. In case of dioxane, the two polar ether groups are the same in magnitude, opposite in direction and separated by two aliphatic $-\mathrm{CH}_{2}-\mathrm{CH}_{2}-$ groups. Assuming the "effective" dielectric constant of DX to be equal to that of THF, the value of $\beta_{n}=36.83$ is found to be in perfect agreement with general trend. The same correction was needed in order to achieve an agreement with the general behaviour for poly(vinyl acetate) and poly(methyl methacrylate) DX solutions. ${ }^{44}$

It is important to ascertain if a similar type of dependence is also observed for nonpolar polymer-solvent systems. In Figure 5, the $\beta=\beta_{n}$ vs. $\delta_{1}$ correlation is shown for cis-polybutadiene $^{37}$ in twenty three linear (e.g., parafins and esters) and nonlinear (e.g., aromatic derivatives, chloroform, and cyclic compounds) solvents. In Figure 6 the $[\eta] \propto \beta=\beta_{n}$ vs. $\delta_{1}$ for natural rubber $^{45}$ is plotted. The data points scatter, but undoubtedly a similar correlation to that for PVC is observed. In addition, the data $^{46}$ for poly(vnyl acetate) and poly(methyl 


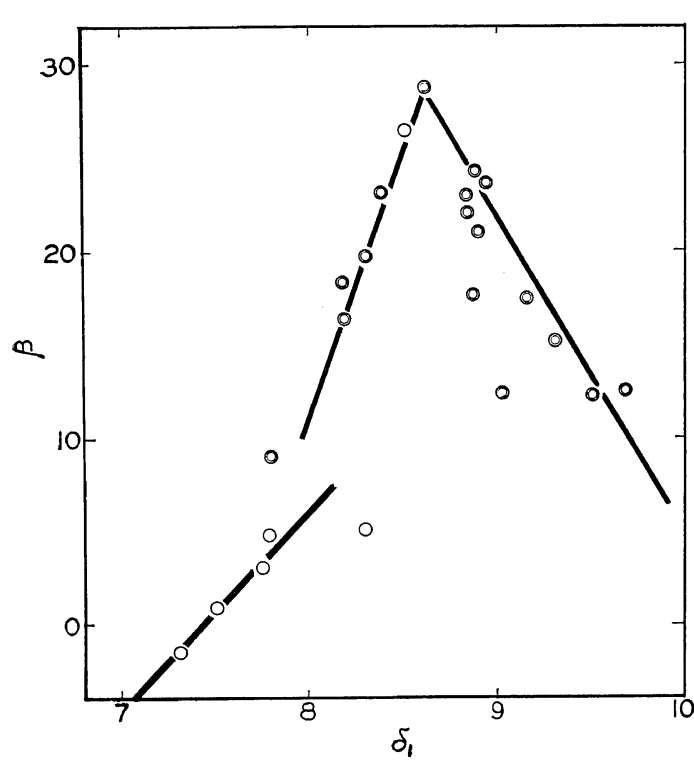

Figure 5. Binary cluster integral $\beta=\beta_{\mathrm{n}} v s$. $\delta_{1}$ for cis-polybutadiene ${ }^{37}$ in linear molecule solvents $(O)$, and in non linear molecule solvents (O).

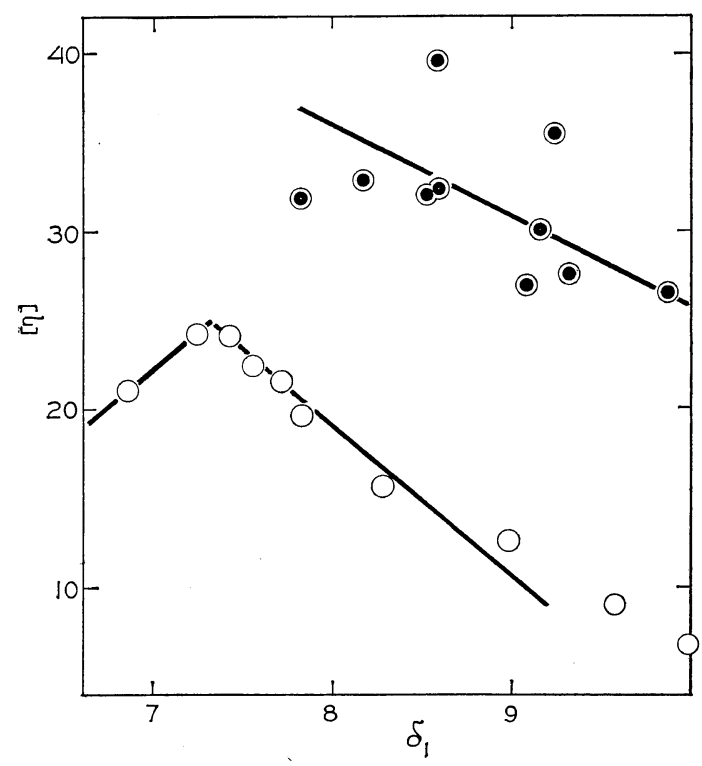

Figure 6. Intrinsic viscosity of natural rubber ${ }^{45}$ vs. $\delta_{1}$ in linear and non linear solvents (see text).

methacrylate), analyzed ${ }^{44}$ in the same way yield a very similar $\beta_{\mathrm{n}}$ vs. $\delta_{1}$ correlation.

\section{Temperature Dependence of $[\eta]$}

In the calculations, the value of $\mathrm{d} \ln K_{\theta} / \mathrm{d} T=$
$2.25 \times 10^{-3}$ was used. $^{20}$ Assuming $I_{25^{\circ}}=1.05 K_{\theta}=$ $1.35 \times 10^{-3}$, the $\beta$ values were computed from the data of Table IV. The temperature dependence of $\varepsilon$ for THF was taken from ref 31 , and that for the other two solvents from ref 29. The temperature dependence of $V_{0}$ was calculated from $\mathrm{d} \ln V_{0} / \mathrm{d} t=1.2 \times 10^{-4}$ and the quoted values of $\rho_{25^{\circ}}=1.385(\mathrm{~g} / \mathrm{ml})$. The results are presented in Table VI.

Table VI. Temperature dependence of $\beta_{n}$ for PVC solution

\begin{tabular}{|c|c|c|c|c|c|c|c|}
\hline \multirow{2}{*}{ Solvent } & \multicolumn{4}{|c|}{$\beta_{\mathrm{n}}, \AA^{3}$} & \multirow{2}{*}{$\beta_{\mathrm{S}}$} & \multirow{2}{*}{$\beta_{\mathrm{H}^{298}}$} & \multirow{2}{*}{$\begin{array}{c}\beta_{\mathrm{n}}^{298} \\
\text { (calcd) }\end{array}$} \\
\hline & $15^{\circ}$ & $25^{\circ}$ & $40^{\circ}$ & $60^{\circ}$ & & & \\
\hline THF & 55.96 & 55.33 & 56.67 & - & 67 & -12 & 57 \\
\hline CB & 36.19 & 43.18 & 48.78 & 55.46 & 157 & -113 & 44 \\
\hline NB & 30.35 & 28.57 & 29.22 & 28.11 & 16 & 15 & 31 \\
\hline
\end{tabular}

From the temperature dependence of $\beta_{n}$, the enthalpic and entropic contributions were computed from the formulas:

$$
\begin{gathered}
\beta_{\mathrm{H}}=-T(\mathrm{~d} \beta / \mathrm{d} T) \\
\beta_{\mathrm{S}}=\mathrm{d}(\beta T) / \mathrm{d} T \\
\beta_{\mathrm{n}}=\beta_{\mathrm{H}}+\beta_{\mathrm{S}}
\end{gathered}
$$

These equations are consistent with the definition of the enthalpic and entropic part of the Flory-Huggins solubility parameter: ${ }^{47}$

$$
\chi_{\mathrm{H}}=\kappa=-T(\mathrm{~d} \chi / \mathrm{d} T)
$$

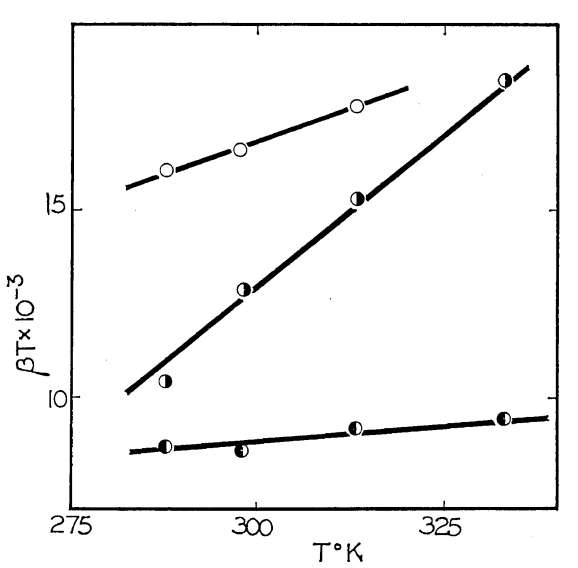

Figure 7. Temperature dependence of $\beta_{\mathrm{n}}$ of poly(vinyl chloride) in tetrahydrofuran (THF), chlorobenzene (CB), and nitrobenzene (NB): $\bigcirc$, THF; - $\mathrm{CB} ; \mathrm{D}, \mathrm{NB}$. 


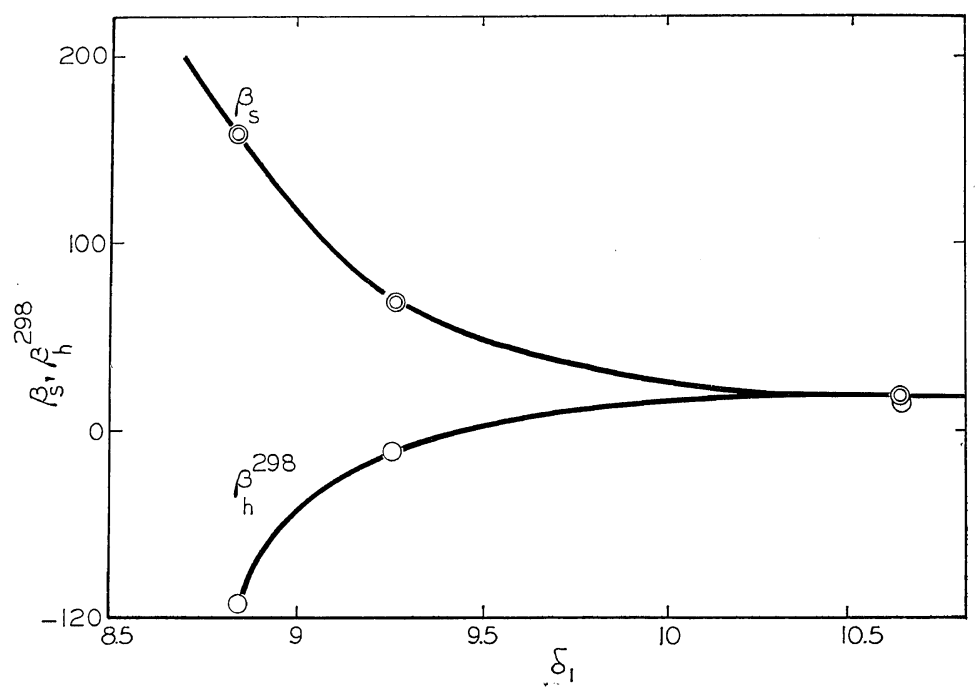

Figure 8. Entropy $\beta_{\mathrm{S}}$ and enthalpy (at $T=298^{\circ} \mathrm{K}$ ) $\beta_{\mathrm{H}^{298}}$ contributions to the non polar interaction paraction parameter $\beta_{\mathrm{n}}$ for poly(vinyl chloride) $v s$. solubility parameter $\delta_{1}$ of the three solvents (see Figure 7).

$$
\begin{gathered}
\chi_{\mathrm{S}}=1 / 2-\Psi=\mathrm{d}(T \chi) / \mathrm{d} T \\
\chi=\chi_{\mathrm{H}}+\chi_{\mathrm{S}}
\end{gathered}
$$

Substitution of eq 3 in eq $24-26$ and taking $\mathrm{d}\left(V_{0}^{2} / V_{1}\right) / \mathrm{d} T \simeq \mathrm{d} V_{0} / \mathrm{d} T=0.009 \simeq 0$

$$
\begin{gathered}
\beta_{\mathrm{H}}=-\left(2 V_{0}^{2} / V_{1}\right) \kappa \\
\beta_{\mathrm{S}}=\left(2 V_{0}^{2} / V_{1}\right) \Psi
\end{gathered}
$$

The values of $\beta_{\mathrm{n}}{ }^{298}$ (calcd) calculated from eq 24-26 and shown in the last column of Table VI, compare quite well with the empirical values at that temperature reported in the third column of the Table.

The data of Figures $4-6$ can be expressed by an approximate empirical relation:

$$
\beta_{11}=E-F\left|\delta_{1}-\delta_{2}\right|
$$

where $E$ and $F$ are the empirical constants for a given system and $E$ (linear) $<E$ (non linear) for all five polymers in solutions investigated up to date. Equation 23 was derived assuming that only the enthalpic parameter depends on $\left(\delta_{1}-\delta_{2}\right)^{2}$. The experimental correlation, eq 32, specifies that $E=$ const. and if these two equations are equivalent, $\Psi$ should also be constant. However, the data of Table VI and Figure 8 show that $\beta_{\mathrm{S}}$ varies from one system to another, $i . e$, eq 23 is inconsistent with the observed correlation.

Alternatively, one can assume that the solubility parameter theory is based on free energy of mixing and write: ${ }^{47}$

$$
\chi=G+\frac{V_{1}}{R T}\left(\delta_{1}-\delta_{2}\right)^{2}
$$

where $G$ is a constant. It is not difficult to see that this correlation also does not satisfy the observed dependencies-from eq 3 and eq 33 we have:

$$
\beta_{\mathrm{n}}=\frac{2 V_{0}^{2}}{V_{1}}(1 / 2-G)-\frac{V_{0}^{2}}{R T}\left(\delta_{1}-\delta_{2}\right)^{2}
$$

The parabolic decrease of $\beta_{\mathrm{n}}$ from its maximum value at $\delta_{1}=\delta_{2}$ has not been observed for any of the investigated polymer-solvent systems. If the reason for this inadequancy is the inapplicability of the Berthelot rule, then an empirical correction similar to that of Funk and Prausnit $^{38}$ should be used. Accordingly, eq 34 should be rewritten as

$$
\beta_{\mathrm{n}}=\frac{2 V_{0}^{2}}{V_{1}}(1 / 2-G)-\frac{V_{0}^{2}}{R T}\left[\left(\delta_{1}-\delta_{2}\right)^{2}+2 l_{12} \delta_{1} \delta_{2}\right]
$$

(where $l_{12}$ is an experimental parameter which was found to depend on the branching of the interacting molecules), or 


$$
E=\frac{2 V_{0}^{2}}{V_{1}}(1 / 2-G)
$$

and

$$
F^{*}=R T F / 2 V_{0}^{2}=\left[\left(\delta_{1}-\delta_{2}\right)^{2}+2 l_{12} \delta_{1} \delta_{2}\right] /\left|\delta_{1}-\delta_{2}\right|
$$

Equations 36 and 37 can be considered as correlations between the molar volume of a solvent and the empirical parameter $G$, in the first case, and between $l_{12}$ and the $\left(\delta_{1}-\delta_{2}\right)$ parameters in the second. Equation $37 \mathrm{can}$ be checked from the data of ref 38 . It is expected that, if the empirical correlation eq 32 and the Funk-Prausnitz assumption are compatible, the $F^{*}$ should be constant for the mixtures: solventsolvents of the same "symmetry" ("symmetry" being understood as a linear or nonlinear molecule). The results are presented in Table VII. It can be seen that the results for small

Table VII. The parameter $F^{*}$ for solute-solvent systems ${ }^{a}$

\begin{tabular}{llccc}
\hline No. Solute & \multicolumn{2}{c}{$F^{*}$ Solvents } & $\begin{array}{c}\text { Source of } \\
\text { the Data }\end{array}$ \\
\cline { 2 - 5 } & Linear & No linear & \\
\hline 1 & Benzene & $2.06 \pm 0.18$ & $3.62 \pm 0.44$ & Ref 38 \\
2 & $\begin{array}{l}\text { Toluene } \\
3\end{array}$ & $1.38 \pm 0.12$ & $2.79 \pm 0.66$ & Ref 38 \\
$\begin{array}{l}\text { 1,4-cis-Poly } \\
\text { butadiene }\end{array}$ & $1.2 \pm 0.5$ & $2.3 \pm 0.5$ & Ref 37 \\
$4 \begin{array}{l}\text { Poly(methy1 } \\
\text { methacrylate) }\end{array}$ & - & $2.0 \pm 0.5$ & Ref 46 \\
5 & $\begin{array}{l}\text { Poly(vinyl acetate) } \\
\text { Poly(vinyl } \\
\text { chloride) }\end{array}$ & - & $2.9 \pm 0.5$ & $\begin{array}{c}\text { Ref 46 } \\
\text { This } \\
\text { work }\end{array}$ \\
\hline
\end{tabular}

a The $F^{*}$ values for benzene and toluene solutions were computed from eq 37; the remaining values from the slope of the $\beta_{\mathrm{n}} v s$. $\delta_{1}$ dependence.

molecular solutions, nonpolar polymer solutions and polar polymer solutions are consistent.

\section{CONCLUSIONS}

The assumption that statistical segment is equivalent to a monomeric unit leads to consistent results at least for poly(vinyl chloride), poly(vinyl acetate), and poly(methyl methacrylate) systems investigated so far. Furthermore, subtracting the polar interaction contribution $\beta_{\theta}$ from the binary cluster integral $\beta$, one is able to calculate the nonpolar interaction parameter, $\beta_{\mathrm{n}}$, which behaves similarly to the total experimental $\beta$ parameter of a nonpolar polymer.

The correlation of $\beta_{\mathrm{n}}$ and the solvent solubility parameter does exist, but the solubility parameter theory must be supplemented by an ill defined "symmetry" factor or with an empirical "branching parameter", $l_{12}$. The similarity of the $\beta_{\mathrm{n}}-\delta_{1}$ dependence between the polymer containing system and those of small molecule solvent solvent types indicates that "symmetry" consideration is equally important to all thermodynamic solubility problems.

The importance of the "symmetry" of molecules may also explain why the Hansen or Bagley methods of separation of the interaction forces does not work, either with $\beta$ or with $\beta_{\mathrm{n}}$.

\section{REFERENCES}

1. G. Tanaka, S. Imai, and H. Yamakawa, $J$. Chem. Phys., 52, 2639 (1970).

2. K. Takashima, G. Tanaka, and H. Yamkawa, Polymer J., 2, 245 (1971).

3. E. F. Casassa and G. C. Berry, Polymer Preprints, 12, 19 (1971).

4. T. Kotaka, T. Tanaka, H. Ohnuma, Y. Murakami, and H. Inagaki, Polymer J., 1, 245 (1970).

5. L. A. Utracki and R. Simha, Macromolecules, 1, 505 (1968).

6. P. J. Flory and S. Fisk, J. Chem. Phys., 44, 2243 (1966).

7. W. H. Stockmayer, J. Polym. Sci., 15, 595 (1955).

8. H. Yamakawa, S. A. Rice, R. Corneliussen, and L. Kotin, J. Chem. Phys., 38, 1759 (1963).

9. H. Yamakawa and G. Tanaka, ibid., 47, 3991 (1967).

10. M. Kurata and H. Yamakawa, ibid., 29, 311 (1958).

11. L A. Utracki and R. Simha, J. Phys. Chem., 67, 1052 (1963).

12. L. A. Utracki, R. Simha, and L. J. Fetters, $J$. Polym. Sci., Part A-2, 6, 2051 (1968).

13. A. Dondos and H. Benoit, Macromolecules, 4, 279 (1971).

14. P. Kratochvil, M. Bohdanecký, K. Šole, M. Kolinský, M. Ryska, and D. Lim, J. Polym. Sci., Part C, 23, 9 (1968).

15. T. Shimanouchi, M. Tasumi and Y. Abe, Makromol. Chem., 86, 43 (1955).

16. J. Štokr, B. Schneider, M. Kolinský and M. Ryska, J. Polym. Sci., Part A-1, 5, 2013 (1967). 


\section{A. Utracki}

17. Yu. V. Glozkovskii, A. N. Zavyalov, V.P. Lebedev, and N.A. Okladnov, Vysokomol. Soedin., Part A, 10, 910 (1968).

18. M. R. Cannon, R. E. Manning, and J. D. Bell, Anal. Chem., 32, 355 (1960).

19. M. Bohdanecký, Coll. Czechoslov. Chem. Commun., 34, 2065 (1969).

20. M. Bohdanecký, V. Petrus and P. Kratochvil, Coll. Czechoslov. Chem. Commun., 34, 1168 (1969).

21. e.g., G. M. Bristow and W. F. Watson, Trans. Faraday Soc., 54, 1731, 1742 (1958).

22. L. A. Utrack1, unpublished results.

23. G. M. Bristow, J. Polym. Sci., 62, S168 (1962).

24. J. A. Manson and L. H. Cragg, Can. J. Chem., 30, 482 (1952).

25. Y. Noguchi, A. Aoki, G. Tanaka, and $\mathbf{H}$. Yamakawa, J. Chem. Phys., 52, 2651 (1970).

26. A. Nakajima, H. Hamada, and S. Hayashi, Makromol. Chem., 95, 40 (1966).

27. A. Kotera, H. Shima, N. Fujisaki, and T. Kobayashi, Bull. Chem. Soc. Japan, 35, 1117 (1962).

28. M. B. Huglin, J. Appl. Polym. Sci., 9, 3963 (1965).

29. A. A. Mayot and E. R. Smith, "Table of Dielectric Constants," NBC Circular No. 514, August 10, 1951.

30. K. L. Hoy, J. Paint Technol., 42, 76 (1970).

31. J. Crossley, S. W. Tucker, and S. Walker, Trans. Faraday Soc., 62, 576 (1966).
32. G. R. Leader and J.F. Gormley, J. Amer. Chem. Soc., 73, 5731 (1951).

33. J. H. Hildebrand and R. L. Scott, "Solubility of Nonelectrolytes", Reinhold Publishers Corp., New York, N. Y., 1955, p 427.

34. C. M. Hansen, Ind. and Eng. Chem., Prod. Res., and Dev., 8, 2 (1969).

35. L. H. Lee, J. Paint Technol., 42, 365 (1970).

36. J. Brandrup and E. H. Immergut, Ed, "Polymer Handbook", Interscience Publisher, New York, 1966.

37. S. K. Bhatnagar, Makromol. Chem., 122, 82 (1969).

38. E. W. Funk and J. M. Prausnitz, Ind. and Eng. Chem., 62, 8 (1970).

39. See ref 33, Chapter 9.

40. E. B. Bagley, T. P. Nelson, and J. M. Scigliano, J. Paint Technol., 43, 35 (1971).

41. J. Biroš, L. Zeman and D. Patterson, Macromolecules, 4, 30 (1971).

42. P. J. Flory, Discussion Faraday Soc., 49, 7 (1970).

43. See ref 33, Chapter 20.

44. L. A. Utracki, J. Appl. Polym. Sci., 16, 1167 (1972).

45. G. M. Bristow and W.F. Watson, Trans. Faraday Soc., 54, 1742 (1958).

46. H. Daoust and M. Rinfret, J. Colloid Sci., 7, 11 (1952).

47. D. Patterson, Rubber Chem. Technol. 40, 1 (1967). 